\title{
Why Do Tamarins Swallow Such Large Seeds? A Response to Heymann's Commentary
}

\author{
Paul A. Garber • Uriel Kitron
}

Received: 5 March 2013 / Accepted: 28 March 2013 / Published online: 18 April 2013

(C) Springer Science+Business Media New York 2013

\begin{abstract}
In a manuscript published several years ago in the International Journal of Primatology we (Garber and Kitron International Journal of Primatology, 18, 523$538,1997)$ offered two hypotheses - a feeding efficiency hypothesis and a curative function hypothesis - to account for the fact that several, if not all, species of tamarin monkeys (Saguinus) commonly swallow very large seeds (mean seed length 1.12$1.47 \mathrm{~cm}$ depending on the tamarin species) that pass through their digestive tract intact. Recently, Heymann (2013), using data from Knogge and Heymann (Folia Primatologica, 74, 33-47, 2003), Müller (2007), and Wenz et al. (Parasitology, 137, 675-684, 2010), attempted to test the curative function hypothesis and argued that there was no support for the contention that seeds passing through the tamarin gut acted to dislodge or expel intestinal parasites. Here we respond to Heymann's commentary. Although we acknowledge the difficulties of testing self-medication hypotheses on wild primates, we also point out that using data sets not originally designed to test such hypotheses directly limits the strength of Heymann's analyses. Moreover, we postulated that the mechanical advantage provided by seeds in expelling parasites was based on the number of large seeds present in the tamarin gut and the volume of seeds present in the tamarin gut, and not simply on whether fecal samples did or did not contain seeds. Finally we question why Heymann (2013) set a threshold for seed length in his analyses at $\geq 0.5 \mathrm{~cm}$ when based on his own data (Knogge and Heymann Folia Primatologica, 74, 33-47, 2003) the mean length of seeds voided by his tamarin study groups exceeded $1.7 \mathrm{~cm}$. We commend Heymann for advancing this discussion; however, we feel that given our current state of knowledge the curative function hypothesis remains a viable explanation to account for seed swallowing in wild tamarins.
\end{abstract}

P. A. Garber $(\bowtie)$

Department of Anthropology and Program in Ecology, Evolution, and Conservation Biology,

University of Illinois, Urbana, IL 61801, USA

e-mail: p-garber@illinois.edu

U. Kitron

Department of Environmental Studies, Emory University, Atlanta, Georgia 30322 
Keywords Parasites $\cdot$ Saguinus $\cdot$ Seed swallowing $\cdot$ Self-medication

In a recent commentary published in the International Journal of Primatology, Eckhard Heymann analyzed a series of data sets to test a hypothesis we proposed (Garber and Kitron 1997) regarding whether large seeds swallowed by small-bodied tamarins (Saguinus spp.) serve a curative function in dislodging intestinal parasites from their gut mucosa. In our original manuscript (Garber and Kitron 1997), we presented data showing that several species of wild tamarins, including Saguinus geoffroyi (Panamanian tamarin) and Saguinus mystax (mustached tamarin), commonly swallow large seeds (mean length of seeds swallowed by $S$. geoffroyi was $1.12 \mathrm{~cm}$ and mean seed length of seeds swallowed by $S$. mystax was $1.19 \mathrm{~cm}$ ). Based on data obtained from seeds voided by wild individuals trapped and released, the tamarins were found to have as many as 13-26 seeds in their gut at one time. The seeds were not digested, and in $>70 \%$ of cases seeds passing through the tamarin gut were intact and viable in germination experiments (Garber 1986, 1994). A related study of Saguinus nigrifrons (formerly $S$. fuscicollis nigrifrons) indicated that even in the smallest tamarin taxa (adult body mass 325-400 g) individuals commonly swallowed seeds averaging $1.47 \mathrm{~cm}$ in length, with the largest seeds $2.5 \mathrm{~cm}$ in length (Garber 1986). Based on these data, we asked the question (Garber and Kitron 1997, p. 523): "Given their small body size and relatively short digestive tract, why do tamarins swallow such large seeds?" Were proposed two hypotheses: 1) swallowing seeds with adhering pulp or an arilate seed coat is more efficient (increased feeding rate) than attempting to manipulate the seed and remove the pulp orally or manually; and 2) the large volume and ballast of seeds contained in the tamarin gut may serve a mechanical function in dislodging or damaging parasites or in sufficiently irritating the gut lining to facilitate a host-immune response that would aid in eliminating parasites (Garber and Kitron 1997).

Heymann (2013, this issue) used data collected from studies by Knogge and Heymann (2003), Müller (2007), and Wenz et al. (2010) to test two predictions arising from our hypothesis. First, the incidence of Prosthenorchis elegans infection ( $P$. elegans is an acanthocephalan hookworm commonly reported in the intestinal tracts of both captive and wild tamarins [Dawson 1976; Wenz et al. 2010]) is expected to decrease during periods in which tamarin feces contain seeds. Second, tamarins infected with these intestinal parasites should swallow seeds $\geq 0.5 \mathrm{~cm}$ in length more often than uninfected individuals (Heymann 2013). With respect to Heymann's commentary, we acknowledge the difficulties of testing self-medication hypotheses in wild primates and commend his attempt to do so. However, we also point out that using data sets not originally designed to test these hypotheses directly may limit the strength of the analyses and results.

Heymann presents data from Knogge and Heymann (2003) that support our observations that wild tamarins swallow very large seeds. The mean length of voided seeds in their study was $1.75 \mathrm{~cm}$ in Saguinus mystax and $1.74 \mathrm{~cm}$ in $S$. nigrifrons. These seeds are absolutely larger than the mean length of seeds voided by howlers (Alouatta seniculus: Julliot 1996), baboons (Papio anubis: Lieberman et al. 1979), gibbons (Hylobates mulleri x agilis: McConkey 2000), red-tailed monkeys (Cercopithecus ascanius: Lambert 1999), blue monkeys (Cercopithecus mitis: 
Kaplan and Moermond 1998), mountain monkeys (Cercopithecus l'hoesti: Kaplan and Moermond 1998), long-tailed macaques (Macaca fuscicularis: Lucas and Corlett 1998), and other primates that are 5-40 times heavier than tamarins. Relatedly, data from Müller (2007) and Wenz et al. (2010) indicate that between $18.4 \%$ and $33.3 \%$ of individual tamarins sampled were infected with Prosthenorchis elegans parasites (based on egg/larvae counts per $100 \mu \mathrm{l}$ of fecal material), and that 48.6-70.2\% of tamarin fecal samples contained seeds. Heymann (2013) reports, however, that there was no correlation between the proportion of fecal samples that contained Prosthenorchis elegans and the proportion of fecal samples containing seeds $\geq 0.5 \mathrm{~cm}$ in length, and that parasite-infected individuals and noninfected individuals did not differ in their proportion of fecal samples that included seeds $\geq 0.5 \mathrm{~cm}$ in length. Moreover, Heymann (2013) argued that given the burrowing morphology of P. elegans, "this makes mechanical dislocation and expelling by seeds unlikely or at least quite difficult; dislocation would result in deep wounds in the gut wall." Based on these data, he concluded that the curative function hypothesis was not supported.

We concur with Heymann that his results do not fit our predictions, but we question whether the data set and analyses presented are suitable for directly testing the curative function hypothesis. His first prediction is that at the population level, as the proportion of fecal samples that contained seeds increased the number of infected individuals should decrease. However, as presented, this prediction is not consistent with the curative function hypothesis. To begin, Garber and Kitron (1997) postulated that the mechanical advantage provided by seeds in expelling parasites was based on the number of large seeds present in the tamarin gut and the volume of seeds present in the tamarin gut, and not simply on whether fecal samples did or did not contain seeds. The presence or absence of seeds is not a sensitive proxy for the size/volume of seeds in the gut. For example, in our publication (Garber and Kitron 1997, Table V) we presented data indicating that the volume of seeds in the digestive tract of Saguinus geoffroyi filled 40-73\% of the volume of their small intestines and the volume of seeds in the digestive tract of S. mystax filled $13-40 \%$ of the volume of their small intestines. In addition, the curative function hypothesis predicts that tamarins swallow large seeds throughout the year both to prevent parasite establishment as well as to dislodge established parasites. We suggested that orthopterans (katydids, grasshoppers, crickets), which are major components of the tamarin diet during all months of the year, are likely vectors of parasite transmission (Garber and Kitron 1997). These insects serve as intermediate hosts for several taxa of parasitic intestinal worms and therefore tamarins are exposed and reexposed to these parasites almost daily.

Heymann's second prediction, that a greater proportion of fecal samples of infected individuals should contain seeds $\geq 0.5 \mathrm{~cm}$ than those of uninfected individuals, also does not fully address the curative function hypothesis. We question why such a low threshold for seed length $(\geq 0.5 \mathrm{~cm})$ was used in his analysis given the author's own data indicating that the mean length of voided seeds was $1.75 \pm 0.59 \mathrm{~cm}$ in Saguinus mystax and $1.74 \pm 0.56 \mathrm{~cm}$ in S. nigrifrons (Knogge and Heymann 2003). Although we acknowledge that many primates commonly drop or spit out rather than swallow seeds $\geq 0.5 \mathrm{~cm}$ in length, this is clearly not the case for tamarins. We suggest that a more robust test of the curative function hypothesis would involve a reanalysis of Heymann's data set to determine if tamarins that swallow several seeds $\geq 1.5 \mathrm{~cm}$ in 
length are less infected with intestinal parasites than individuals that swallow fewer and smaller seeds, or whether the total volume of seeds in tamarin feces is a stronger predictor of a reduction in parasite prevalence.

Further, the Wenz et al. (2010) parasite study examined fecal samples obtained from 43 individual tamarins during the dry season months of July-September 2007. These authors used microscopic evaluation to identify the presence and type of eggs and larvae in the fecal samples. Wenz et al. (2010) caution that many factors can affect host susceptibility to parasite infection, and that many parasites shed eggs or larvae only at particular times in their developmental cycle. In this regard, even multiple host fecal samples (mean number of samples per individual ranged from 3.2 to 6.2) collected during a limited period of the year may not provide an accurate assessment of an individual's parasite load.

Wenz et al. (2010) identified seven parasite taxa in the tamarin feces including Prosthenorchis elegans, possibly Hymenolepis cebidarum, cestodes, large rurids (possibly Gongylonema sp.), spirurids, nematode larvae (possibly from the order Rhabditida [Strongyloides sp.] or the superfamily Metastrongiloidea [Filaroides sp. and Angiostrongylus sp.]), and strongylids (possibly Molineus sp. or Strongyloides cebus). Heymann (2013) argues that the Wenz et al. (2010) study did not find excreted parasites in tamarin feces. However, the probability of finding whole worms or even parts of a worm in a given fecal sample is small, given that even eggs produced in the thousands by adult worms are often not detected in feces. Moreover, Wenz et al. (2010) compared parasite prevalence between tamarin groups inhabiting forest areas away from human contact and groups whose home range overlapped with cultivated fields and gardens. They found that with increased contact with human settlements, tamarins exhibited an increase in the number of eggs and prevalence of Prosthenorchis elegans. Although there are many possible explanations to account for the reduced prevalence and intensity of Prosthenorchis elegans infection in the forest groups, one that is consistent with the curative function hypothesis is that the forest groups may have continued to rely on their natural behavior of swallowing the seeds of wild fruits whereas tamarins that consumed fruits from gardens may decrease this behavior in response to the trend of extreme increases in both pulp mass and seed size that characterizes many human-cultivated fruits (Fuller and Allaby 2009).

Finally, Heymann (2013) argued that given the specialized burrowing morphology of Prosthenorchis elegans and other parasitic worms present in the tamarin gut, even a large volume of seeds moving through the digestive tract would not be effective in dislodging parasites embedded in the gut wall. However, although the proboscis of acanthocephala is one of the best-developed helminth attachment organs, worms are susceptible to dislodging with the passage of food, and the risk of dislodgement is greater for larger worms in endothermic hosts (Poulin 2007). The greater food intake required for endothermy and the higher rates of peristalsis and other movements associated with the passage of more food along the gut mean that intestinal worms in endotherms face a greater risk of being physically removed from their attachment site (Poulin 2007). Thus, the large seeds that tamarins pass through their guts are likely not only to act as dislodging agents, but also to damage the nonattached body parts of the parasites.

In conclusion, the question of why small-bodied tamarin monkeys habitually swallow and void intact such large seeds requires continued investigation. We encourage researchers working in both captive and field settings to collaborate in 
this research and rigorously test a number of alternative hypotheses to explain this behavior. Moreover, the "feeding efficiency" hypothesis and the "curative function" hypothesis offer clear alternative predictions to account for seed swallowing. We commend Dr. Heymann for advancing this discussion; however, we feel that given our current state of knowledge the curative function hypothesis remains a viable explanation to account for seed swallowing in wild tamarins.

Acknowledgments P. A. Garber thanks Chrissie McKenney, Joanna Setchell, and an anonymous reviewer for constructive comments on an earlier draft of this manuscript, and Chrissie McKenney, Sara Garber, and Jenni Garber for their continued support and guidance. Walter Mermao and Eriberto Mermao provided critical field assistance in collecting seeds from wild tamarins.

\section{References}

Dawson, G. A. (1976). Behavioral ecology of the Panamanian tamarin, Saguinus oedipus (Callitrichidea, Primates). Ph.D. dissertation, Michigan State University.

Fuller, D. Q., \& Allaby, R. (2009). Domestication: shattering, germination, and seasonality in evolution under cultivation. Annual Plant Reviews, 38, 238-295.

Garber, P. A. (1986). The ecology of seed dispersal in two species of callitrichid primates (Saguinus mystax and Saguinus fuscicollis). American Journal of Primatology, 10, 155-170.

Garber, P. A. (1994). Aspects of fruit eating and seed dispersal in Panamanian (Saguinus geoffroyi) and moustached tamarins (Saguinus mystax). Regional Conference Proceedings of the American Zoo and Aquarium Association, pp. 364-369.

Garber, P. A., \& Kitron, U. (1997). Seed swallowing in tamarins: evidence of a curative function or enhanced foraging efficiency? International Journal of Primatology, 18, 523-538.

Heymann, E. W. (2013). Can seeds help to expel parasites? A comment on the Garber.

Julliot, C. (1996). Seed dispersal by red howling monkeys (Alouatta seniculus) in the tropical rain forest of French Guiana. International Journal of Primatology, 17, 239-258.

Kaplan, B. A., \& Moermond, T. C. (1998). Variation in seed handling by two species of forest monkeys in Rwanda. American Journal of Primatology, 45, 83-101.

Knogge, C., \& Heymann, E. W. (2003). Seed dispersal by sympatric tamarins, Saguinus mystax and Saguinus fuscicollis: diversity and characteristics of plant species. Folia Primatologica, 74, 33-47.

Lambert, J. E. (1999). Seed handling in chimpanzees (Pan troglodytes) and redtail monkeys (Cercopithecus ascanius): implications for understanding hominoid and cercopithecine fruit-processing strategies and seed dispersal. American Journal of Physical Anthropology, 109, 365-386.

Lieberman, D., Hall, J. B., Swaine, M. D., \& Lieberman, M. (1979). Seed dispersal by baboons in the Shai Hills, Ghana. Ecology, 60, 65-75.

Lucas, P. W., \& Corlett, R. T. (1998). Seed dispersal by long-tailed macaques. American Journal of Primatology, 45, 29-44.

McConkey, K. R. (2000). Primary seed shadow generated by gibbons in the rain forests of Barito Ulu, central Borneo. American Journal of Primatology, 52, 13-29.

Müller, B. (2007). Determinants of the diversity of intestinal parasite communities in sympatric New World primates (Saguinus mystax, Saguinus fuscicollis, Callicebus cupreus). Doctoral dissertation, Tierärztliche Hochschule Hannover.

Poulin, R. (2007). Investing in attachment: evolution of attachment structures in parasites. Biological Journal of the Linnean Society, 90, 637-645.

Wenz, A., Heymann, E. W., Petney, T. N., \& Taraschewski, H. F. (2010). The influence of human settlements on the parasite community in two species of Peruvian tamarin. Parasitology, 137, 675-684. 